\title{
PHẪU THUÂT CẮT TỬ CUNG CẤP CỨU DO BĂNG HUYẾT SAU SINH NGÃ ÂM ĐẠO NẶNG TẠI BỆNH VIỆN TỪ DŨ
}

\author{
Bùi Đặng Lan Hương ${ }^{1}$, Phạm Việt Thanh ${ }^{1}$, Phạm Thanh Hải1, \\ Nguyễn Long ${ }^{1}$, Nguyễn Đình Hiển ${ }^{1}$
}

\section{TÓM TẮT}

Muc tiêu: Phân tích đăc điểm và kết cuc các sản phụ phải phẫu thuât cắt tử cung cấp cứu do băng huyết sau sinh ngã ẩm đạo năng tại Bệnh viện Từ Dũ. Đối tượng và phương pháp: Ñghiển cứu hồi cứu báo cáo loạt ca các trường hợp phấu thuật cắt tử cung cấp cứu do băng huyết sau sinh ngã âm đạo năng tại Bệnh viện Từ Dũ trong thời gian từ từ $1 / 8 / 2019$ đến tháng 30/12/2019. Các đặc điểm được ghi nhận bao gồm: đặc điểm dịch tễ học, tiền căn sản phự khoa, đăc điểm thai kỳ lần này, đăc điểm cuôc sinh và BHSS. Kết quả: Trong khoảng thời gian nghiên cứu 5 tháng, có 177 trường hợp băng huyết sau sinh ngã âm đao nặng tại Bệnh viện Từ Dũ. Trong đó, chúng tôi trích lục đưởc 7 trường hợp có phẫu thuật cắt tử cung cấp cứu để cứu me sau khi các điều trị nội và ngoại khoa bảo tồn thất bai (chiếm 3,9\%). Toàn bô đều đước điều trị cứu mạng mẹ thành công sau phẫu thuật cắt tử cung cấp cứu. Kết luận: BHSS nặng tuy chiếm tỉ lệ nhỏ nhưng là một nhóm bệnh cảnh quan trọng, góp phần lớn vào gánh nặng bệnh tật và tử vong do BHSS. Tuy đã có nhiều tiến bộ trong kĩ thuật y tế và phẫu thuật nhưng cắt tử cung cấp cứu vẫn là phương pháp điều trị quan trọng trong BHSS nặng không đáp ứng điều trị ban đâu.

Tư khoá: Băng huyết sau sinh, Cắt tử cung cấp cứu, Sinh ngã âm đạo.

\section{SUMMARY}

\section{EMERGENCY PERIPARTUM HYSTERECTOMY FOR SEVERE POSTPARTUM HEMORRHAGE FOLLOWING VAGINAL DELIVERY AT TU DU HOSPITAL \\ Objective: To analyze the characteristics and outcomes of the emergency peripartum hysterectomies performed at $\mathrm{Tu} \mathrm{Du}$ Hospital. Subjects and methods: This retrospective case series included all women undergone emergency peripartum hysterectomies for severe PPH following vaginal delivery at Tu Du Hospital between 1 August and 20 December 2019. The characteristics consisted of epidemiologic characteristics, obstetric and gynecologic history, this pregnancy, delivery, and PPH characteristics. Results: In the 5-month period of study, there were 177 severe PPH following vaginal delivery cases at Tu Du Hospital. Among them, we identified 7 cases (3.9\%) undergone emergency}

\section{${ }^{1}$ Bênhh viện Từ Dũ}

Chịu trách nhiệm chính: Bùi Đặng Lan Hương

Email: buitunghiep2@gmail.com

Ngày nhận bài: 1/11/2020

Ngày phản biện khoa học: 20/11/2020

Ngày duyệt bài: 5/12/2020 peripartum hysterectomy after failing with less invasive treatments. All were successfully treated after the emergency hysterectomy. Conclusions: Although severe PPH accounts for a small percentage, it contributes significantly to the morbidity and mortality rate. There have been many advances in medical and surgical techniques but emergency peripartum hysterectomy remains an essential intervention for severe PPH that is unresponsive to primary treatment.

Keywords: Postpartum hemorrhage, Emergency hysterectomy, Vaginal delivery.

\section{I. ĐĂT VẤN ĐỀ}

Băng huyết sau sinh (BHSS) là một biến chứng sản khoa tiềm tàng và có thể nhanh chóng đe dọa tính mạng người mẹ, dẫn đến các biến chứng cấp tính nặng nề khác như: shock giảm thể tích, rối loạn đông máu, suy gan, suy thận và suy hô hấp. Nó là nguyên nhân hàng đầu gây tử vong mẹ trên toàn thế giới. Tại Việt Nam, theo nghiên cứu của Bộ Y tế năm 2010 tại các tỉnh đại diện cho 7 vùng kinh tế nước ta, số tử vong mẹ toàn thể trong toàn quốc được ước tính là 165/100.000 trường hợp sinh sống, trong đó BHSS chiếm tỉ lệ 31\%.

BHSS nguyên phát được chẩn đoán khi có mất máu từ $500 \mathrm{ml}$ trở lên trong vòng 24 giờ sau sanh. Ở những thai kỳ bình thường, nhờ cơ chế gia tăng thể tích máu sinh lý để đáp ứng cho sự phát triển thai nhi, tổng lượng máu ở người mẹ có thể gia tăng từ 30-60\% so với bình thường, nhờ đó tổng trạng của sản phụ có thể thay đổi không nhiêuu và hồi phục hoàn toàn ở những trường hợp BHSS nhẹ đến trung bình. Tuy nhiên, BHSS mức độ nặng lại liên quan đáng kể đến bệnh suất và các can thiệp nội - ngoại khoa: truyên máu, phẫu thuật và nhập khoa hồi sức tích cực. BHSS nặng có nhiều định nghĩa khác nhau theo y văn: $\geq 1000 \mathrm{ml}, \geq 1500 \mathrm{ml}$, và $>2000 \mathrm{ml}$. Một số tác giả còn bao gồm thêm các yếu tố khác như có can thiệp cắt tử cung hay truyền máu [1].

Mặc dù đã có nhiêuu tiến bộ trong việc điêuu trị nội khoa và phẫu thuật bảo tồn đối với những trường hợp BHSS nặng, nhưng phẫu thuật cắt tử cung cấp cứu vẫn là thủ thuật cứu mạng trong xử trí BHSS khó chữa không đáp ứng với điều trị bảo tồn. Mục tiêu của nghiên cứu này là phân tích đặc điểm và kết cục các sản phụ phải phẫu thuật cắt tử cung cấp cứu do băng huyết sau sinh ngã âm đạo nặng. 


\section{II. ĐỐI TƯƠ'NG VÀ PHƯƠNG PHÁP NGHIÊN CỨU}

Đây là nghiên cứu hồi cứu báo cáo loạt ca. Tại Bệnh viện Từ Dũ, Khoa Sinh sử dụng phần mềm theo dõi BHSS để xuất danh sách các trường hợp BHSS nặng (máu mất $\geq 1000 \mathrm{ml}$ ). Tất cả các trường hợp phẫu thuật cắt tử cung cấp cứu do băng huyết sau sinh ngã âm đạo nặng tại Bệnh viện Từ Dũ trong thời gian từ 1/8/2019 đến tháng 30/12/2019 đều được xác định qua trích lục hồ sơ trong danh sách này. Phấu thuâat cắt tử cung cấp cứu được định nghĩa là khi tiến hành cắt tử cung trong vòng 24 giờ sau sanh [2].

Tiêu chuẩn loai là: thai phu là trẻ vị thành niên, thai dị tật bẩm sinh phải chấm dứt thai kỳ, thai phụ dị tật bẩm sinh đường sinh dục, có bệnh lý ác tính và hồ sơ không đủ dữ kiện.

Các thông tin được thu thâp bao gồm: đặc điểm dich tể học, tiền căn sản phụ khoa, đặc điểm thai kỳ lần này, đặc điểm cuộc sinh và BHSS. Số liệu thu thập được nhập và xử lý trên phần mềm thống kê y sinh học SPSS 22.0.

\section{KẾT QUẢ NGHIÊN CỨU}

Từ 1/8/2019 đến tháng 30/12/2019, có 177 trường hợp băng huyết sau sinh ngã âm đạo nặng tại Bênh viện Từ Dũ. Trong đó, 7 trường hợp có phẫu thuật cắt tử cung cấp cứu sau khi các điều trị không phẫu thuật thất bại (chiếm $3,9 \%$ ). Toàn bô các ca đều được điều trị thành công sau phẫu thuật cắt tử cung cấp cứu, không ghi nhận có trường hợp nào tử vong.

Đặc điểm sinh của các trường hợp băng huyết sau sinh ngã âm đạo nặng có phẫu thuật cắt tử cung cấp cứu được ghi nhận trong Bảng 1.

Toàn bộ các trường hợp này đều là đơn thai, thai tự nhiên, không có tiên căn BHSS, truyền máu, mổ lấy thai, sử dụng thuốc kháng đông, u xơ tử cung, không tiền sản giật nặng/hội chứng HELLP. Tuổi các thai phụ từ 28-42 tuổi. Cân nặng thai nhi nhỏ nhất là 2900 gram, nặng nhất là 3900 gram. Hai ca được khởi phát chuyển dạ bằng sonde Foley, còn lại là vào chuyển dạ tự nhiên. Ba ca được tăng co bằng Oxytocin. Một trường hợp sanh forceps do tim thai chậm và 1 trường hợp sanh forceps do thai phụ rặn không chuyển. Không ghi nhận trường hợp nào tử vong. Hai ca không cắt tầng sinh môn.

Bảng 1. Đặc điểm sinh của các trường hợp băng huyết sau sinh ngã âm đạo nặng có phẫu thuật cắt tử cung cẩp cứu

\begin{tabular}{|c|c|c|c|c|c|c|c|c|}
\hline $\begin{array}{l}\text { Bênh } \\
\text { nhân }\end{array}$ & $\begin{array}{l}\text { Tuối } \\
\text { thai } \\
\text { phụ }\end{array}$ & Para & $\begin{array}{c}\text { BMI } \\
\left(\mathrm{kg} / \mathrm{m}^{2}\right)\end{array}$ & $\begin{array}{c}\text { Cân năng } \\
\text { thai nhi } \\
\text { (gram) }\end{array}$ & $\begin{array}{l}\text { Khởi phát } \\
\text { chuyển dạ }\end{array}$ & $\begin{array}{c}\text { Tăng } \\
\text { co }\end{array}$ & $\begin{array}{l}\text { Phương } \\
\text { pháp sinh }\end{array}$ & $\begin{array}{l}\text { Căt tâng } \\
\text { sinh } \\
\text { môn }\end{array}$ \\
\hline 1 & 35 & 2012 & 20 & 3600 & sonde Foley & Không & Sinh forceps & Có \\
\hline 2 & 42 & 20 & 2. & & & Có & & Không \\
\hline 3 & 39 & 30 & 10 & & & & & Có \\
\hline 4 & 38 & 0101 & 27 & 3900 & & Không & ing & Không \\
\hline 5 & 36 & 1001 & 24 & 3000 & Tự nhiên & Có & Sinh thường & Có \\
\hline 6 & 33 & 0010 & 23 & & & Không & rceps & Có \\
\hline & & & 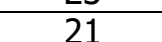 & & & & 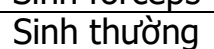 & Co \\
\hline
\end{tabular}

Đặc điểm trong BHSS nă̆ng của các trường hợp phẩu thuật cắt tử cung cấp cứu được ghi nhận trong Bảng 2. Toàn bộ các ca đều có đờ tử cung là 1 trong các nguyên nhân dẫn đến BHSS nặng. Nguyên nhân đi kèm khác là tổn thương đường sinh dục và rối loạn đông máu. Tổng lượng máu mất ít nhất là $1400 \mathrm{ml}$, nhiều nhất là $3700 \mathrm{ml}$. Có $5 \mathrm{ca}$ được tiến hành đặt bóng chèn và $6 \mathrm{ca}$ thắt động mạch cổ tử cung. Chỉ có 1 ca tiến hành thắt động mạch tử cung và 1 ca thắt động mạch hạ vị.

Bảng 2. Đặc điểm trong BHSS nặng của các trường hợp phẫu thuật cắt tử cung cấp cứu

\begin{tabular}{|c|c|c|c|c|c|c|c|c|c|c|}
\hline $\begin{array}{l}\text { Bênhh } \\
\text { nhânn }\end{array}$ & $\begin{array}{l}\text { hân độ } \\
\text { rách } \\
\text { tâng } \\
\text { sinh } \\
\text { môn } \\
\end{array}$ & $\begin{array}{c}\text { Nguyên } \\
\text { nhân BHSS } \\
\text { nặng }\end{array}$ & $\begin{array}{l}\text { Máu } \\
\text { mất } \\
\text { sau } \\
\text { sinh } \\
(\mathrm{ml})\end{array}$ & $\begin{array}{c}\text { Máu mất } \\
\text { trước } \\
\text { mố }(\mathrm{ml})\end{array}$ & $\begin{array}{c}\text { Máu mất } \\
\text { trong } \\
\text { mổ }(\mathrm{ml})\end{array}$ & $\begin{array}{c}\text { Tổng } \\
\text { lượng } \\
\text { máu mất } \\
\text { (ml) }\end{array}$ & $\begin{array}{c}\text { Thắt } \\
\text { động } \\
\text { mạch cổ } \\
\text { tứ cung }\end{array}$ & $\begin{array}{l}\text { Đắt bóng } \\
\text { chèn lòng } \\
\text { tử cung }\end{array}$ & $\begin{array}{c}\text { Thắt động } \\
\text { mạch tử } \\
\text { cung }\end{array}$ & $\begin{array}{c}\text { Thắt } \\
\text { động } \\
\text { mạch hạ } \\
\text { vị }\end{array}$ \\
\hline 1 & 2 & $\begin{array}{l}\text { Đờ tứ cung } \\
\text { + Rối loạn } \\
\text { đông máu }\end{array}$ & 400 & 3100 & 200 & 3700 & Có & Có & Không & Không \\
\hline 2 & 2 & $\begin{array}{l}\text { Đờ tứ cung } \\
\text { + Rối loaan } \\
\text { đông máu }\end{array}$ & 100 & 900 & 400 & 1400 & Có & Có & Có & Không \\
\hline 3 & 2 & Đờ tứ cung & 200 & 1900 & 300 & 2400 & Có & Có & Không & Không \\
\hline
\end{tabular}


TẠP CHÍ Y HỌC VIẸT NAM TẠP 498 - THÁNG 1 - SÓ 1 - 2021

\begin{tabular}{|c|c|c|c|c|c|c|c|c|c|c|}
\hline 4 & 1 & $\begin{array}{l}\text { Đờ tử cung } \\
\text { + Tổn } \\
\text { thương sinh } \\
\text { dục } \\
\end{array}$ & 300 & 1400 & 350 & 2050 & Có & Có & Không & Không \\
\hline 5 & 2 & $\begin{array}{l}\text { Đờ tử cung } \\
+ \text { Tổn } \\
\text { thương sinh } \\
\text { dục }\end{array}$ & 250 & 1450 & 1700 & 3400 & Có & Không & Không & Có \\
\hline 6 & 2 & $\begin{array}{l}\text { Đờ tử cung } \\
\text { + Rối loạn } \\
\text { đông máu }\end{array}$ & 800 & 1400 & 700 & 2900 & Không & Không & Không & Không \\
\hline 7 & 2 & $\begin{array}{l}\text { Đờ tứ cung } \\
\text { + Rối loạn } \\
\text { đông máu }\end{array}$ & 200 & 1900 & 400 & 2500 & Có & Có & Không & Không \\
\hline
\end{tabular}

\section{BÀN LUÂ̂N}

Tỉ lệ phẫu thuật cắt tử cung cấp cứu chu sinh ghi nhận theo y văn thay đổi từ 0,2 đến 1,5 trên 1000 ca sanh. Lý do cho sự thay đổi này có thể do hướng xử trí và kinh nghiệm của các bác sĩ sản khoa khác nhau. Trong nghiên của chúng tôi tỉ lê phẫu thuật cắt tử cung là 3,9\%, cao hơn rất nhiều so với trong y văn vì chúng tôi chỉ xét trong nhóm các bệnh nhân có BHSS nặng, nguy cơ không đáp ứng với các điều trị bảo tồn cao và cần phải có biện pháp điều trị dứt điểm càng sớm càng tốt.

Về yếu tố nguy cơ liên quan BHSS nặng, tác giả Lill Trine Nyflot báo cáo yếu tố nguy cơ mạnh nhất là tiền sử BHSS nặng, ngoài ra còn có: sử dụng thuốc chống đông, thiếu máu lúc nhập viện, tiền sản giật nặng hoặc hội chứng HELLP, u xơ tử cung, đa thai và có thai do hố trợ sinh sản [3]. Tác giả Stones còn báo cáo các yểu tố nguy cơ khác: đa sản (từ 4 con trở lên), tuổi me <20 tuổi hoặc $>35$ tuổi. Trong nghiên cứu của chúng tôi, 7 ca đều không ghi nhận các đặc điểm: tiên căn BHSS, sử dung thuốc kháng đông, thiếu máu lúc nhập viện, u xơ tử cung, có thai do hỗ trợ sinh sản, mắc tiền sản giật nặng/hội chứng HELLP, đa sản, đa thai và tuổi $<20$ tuổi. Có 4 ca tuổi >35 tuổi. Ở phu nữ lớn tuổi, ngoài nguy cơ mắc tiền sản giật nặng/hội chứng HELLP, nhau bám thấp/nhau cài răng lược và rặn không tốt làm kéo dài chuyển dạ hoặc hỗ trợ sanh giúp, sự giảm biểu hiên của các gen quy định truyền tín hiệu và đáp ứng của oxytocin ở cơ tử cung được coi là cơ chế sinh học phân tử dẫn đến tăng nguy cơ BHSS năhng [4].

Các yếu tố như khởi phát chuyển dạ và tăng co bằng Oxytocin vẫn chưa được khẳng định rõ ràng là có nguy cơ với BHSS nặng hay không [3]. Người ta cho rằng giảm độ nhạy của thụ thể Oxytocin sau khởi phát chuyển dạ hoặc tăng co bằng Oxytocin có thể gây đờ tử cung dẫn đến
BHSS. Trong nghiên cứu của chúng tôi, có $2 / 7 \mathrm{ca}$ được tiến hành đặt sonde foley để khởi phát chuyển da và $3 / 7$ ca được chỉ định oxytocin tăng co trong chuyển dạ và các ca tăng co này đều vào chuyển dạ tự nhiên.

Trong $7 \mathrm{ca}$, tổng lượng máu mất ít nhất $1400 \mathrm{ml}$, nhiều nhất là $3700 \mathrm{ml}$. Lượng máu mất và tốc độ máu mất ảnh hưởng rất nhiều đến hướng can thiệp điều trị xâm lấn của BHSS: tính xâm lấn và mức độ an toàn của kĩ thuật. Các biện pháp điều trị BHSS xâm lấn bao gồm: thắt các mạch máu cung cấp cho tử cung: động mạch tử cung, động mạch buồng trứng, động mạch hạ vị, khâu ép tử cung, tắc động mạch chọn lọc và cắt tử cung.

Can thiệp thắt động mạch hạ vị là một kỹ thuật ngoại khoa nâng cao do cần bóc tách vùng châu phức tạp trong điều kiện thời gian ngắn và phẫu trường có thể chảy máu rất nhiều, nguy cơ cao tổn thương mạch máu kế cận, đòi hỏi phẫu thuật viên phải có kinh nghiệm. Nhiều tỷ lệ thành công khác nhau đã được báo giá trong các loạt trường hợp khác nhau. Việc thắt các động mạch này khồng cản trở chức năng sinh sản trong tương lai [6]. Nghiên cứu của chúng tôi có 1 ca thắt động mạch hạ vị.

Tác giả Christopher B-Lynch đã đề cử 1 phương pháp khâu ép tử cung: ép tử cung với 2 mũi khâu doc theo truc dài của nó và ngăn không cho tử cung giän ra và bị ứ đầy máu. Trong kĩ thuật này, lòng tử cung sẽ bị may xuyên. Đã có một số nghiên cứu loạt ca báo cáo thành công với việc cầm máu BHSS nhờ kĩ thuật này [7]. Các ca mổ lấy thai có nhau cài răng lược tại Bệnh viện Từ Dũ thường sử dụng kĩ thuật khâu ép tử cung B-Lynch trong trường hợp bảo tồn tử cung. Trong 7 ca chúng tôi không có ca nào tiến hành kĩ thuật này.

Tắc động mạch chọn lọc là một phương pháp can thiệp đòi hỏi cơ sở thiết bị chẩn đoán hình 
ảnh hỗ trợ trong phòng mổ và chỉ được chỉ định trong những trường hợp BHSS bệnh nhân tương đối ổn định. Chỉ định sản khoa cho tắc động mạch chọn lọc được báo cáo chủ yễu là do tổn thương đường sinh dục và đờ tử cung với tỉ lệ thành công lần lượt là $90 \%$ và $100 \%$ [8]. Hiện tại ở Bệnh viện Từ Dũ chưa áp dụng phương pháp này vào phác đồ điều trị BHSS.

Sau thất bại với các biện pháp điều trị ít xâm lấn ban đầu, cắt tử cung cấp cứu là biện pháp điều trị nên được tiến hành ngay, đặc biệt nếu BHSS nặng có liên quan đến nhau bong non hoặc võ tử cung. Trong nghiên cứu của chúng tôi, tất cả các ca trước khi cắt tử cung cấp cứu đều được sử dụng các thuốc hố trợ gò tử cung (Oxytocin, Misoprostol, Ergotamin, Duratocin và Endoprost) và cầm máu (Transamic), có $5 \mathrm{ca}$ được đă̆t bóng chèn lòng tử cung. Tất cả 7 đều được cắt tử cung toàn phần. Việc cắt tử cung cấp cứu trong BHSS bán phần gần đây được gợi ý vì kĩ thuật phẫu thuật nhanh hơn và ít biển chứng tổn thương cơ quan lân cận hơn [2]. Tuy nhiên nó có nhiều nguy cơ vì chảy máu ở vùng cổ tử cung vẫn có thể còn đang tiếp diễn. Các biến chứng có thể liên quan đến phẩu thuật cắt tử cung cấp cứu bao gồm: tổn thương bàng quang, niệu quản, nhiễm trùng, xuất huyết và tử vong mẹ [2].

\section{KẾT LUÂ̂N}

Phụ nữ bị BHSS nặng tuy chiếm tỉ lệ nhỏ nhưng là một nhóm bệnh cảnh quan trọng, góp phần lớn vào gánh nặng bệnh do BHSS. Tuy đã có nhiều tiến bộ trong kĩ thuật y tế và phẫu thuật nhưng phẫu thuật cắt tử cung cấp cứu vẫn là phương pháp điều trị quan trọng trong BHSS nặng không đáp ứng điều trị ban đầu.

\section{TÀI LIÊU THAM KHẢO}

1. A. Mehrabadi, J. A. Hutcheon, L. Lee, R. M. Liston, and K. S. Joseph, "Trends in postpartum hemorrhage from 2000 to 2009: A populationbased study," BMC Pregnancy Childbirth, 2012.

2. J. Smith and H. A. Mousa, "Peripartum hysterectomy for primary postpartum haemorrhage: Incidence and maternal morbidity," J. Obstet. Gynaecol. (Lahore)., 2007.

3. L. T. Nyfløt et al., "Risk factors for severe postpartum hemorrhage: A case-control study," BMC Pregnancy Childbirth, 2017.

4. A. S. Oberg, S. Hernandez-Diaz, K. Palmsten, C. Almqvist, and B. T. Bateman, "Patterns of recurrence of postpartum hemorrhage in a large population-based cohort," in American Journal of Obstetrics and Gynecology, 2014.

5. S. L. Clark, S. Y. Yeh, J. P. Phelan, S. Bruce, and R. H. Paul, "Emergency hysterectomy for obstetric hemorrhage," Obstet. Gynecol., 1984.

6. H. Camuzcuoglu, H. Toy, M. Vural, F. Yildiz, and H. Aydin, "Internal iliac artery ligation for severe postpartum hemorrhage and severe hemorrhage after postpartum hysterectomy," ]. Obstet. Gynaecol. Res., 2010.

7. E. El-Hamamy, A. Wright, and C. B-Lynch, "The B-Lynch suture technique for postpartum haemorrhage: A decade of experience and outcome," Journal of Obstetrics and Gynaecology. 2009.

8. J. J. Merland et al., "Place of emergency arterial embolisation in obstetric haemorrhage about 16 personal cases," in European Journal of Obstetrics and Gynecology and Reproductive Biology, 1996.

\section{TẠO HÌNH TAI NHỎ SỚM, MộT THÌ BẰNG KHUNG SỤN NHÂN TẠO VÀ TỰ THÂN CÓ NộI SOI HỖ TRỢ TẠI HÀ NộI}

\section{Nguyễn Hồng Hà*, Trần Thị Thanh Huyền*, Nguyễn Thu Hằng*, Nguyễn Thị Hương Giang*, Ngô Hải Sơn*}

\section{TÓM TẮT}

Khuyết vành tai là một tổn thương phức tạp, nó có nhiều dạng khác nhau từ khuyết một phần hoắc toàn bộ vành tai do bẩm sinh. Cấu trúc giải phẫu đă̆c biệt của tai cũng như hình thể 3 chiều của nó khiến cho việc tao hình tai luôn đặc biệt khó khăn. Chúng tôi

\footnotetext{
*Bệnh viện Việt Đức, Hà Nội

Chịu trách nhiệm chính: Nguyễn Hồng Hà

Email: nhadr4@gmail.com

Ngày nhận bài: 30/11/2020

Ngày phản biện khoa học: 15/12/2020

Ngày duyệt bài: 22/12/2020
}

muốn báo cáo kết quả phẫu thuật tạo hình tai nhỏ sớm, một thì bằng khung sụn nhân tạo Medpor và sụn sườn tự thân tại Hà Nội, Việt Nam. Để gia tăng tị lệ thành công và giảm biến chứng phẫu thuật, việ̂́c bóc tách vạt cân thái dương đỉnh được thực hiện bắng kỹ thuật nội soi chỉ với 1 lỗ duy nhất. Trước mổ bệnh nhân được kiểm tra thính lực để có phương án điều trị hỗ trợ nghe phối hợp. Sau mổ tất cả các bệnh nhân và gia đình đều hài lòng với kết quả ngay sau phẫu thuật. Với tỉ lệ biến chứng thấp, kết quả thâm mỹ và mức độ hài lòng cao của người bênh khiến các kỹ thuật này đã̉ mang đến những lựa chọn tối ưu trong điêu trị dị tật và khuyết hổng vùng tai.

Tư khóa: Tạo hình tai, tai nhỏ bẩm sinh, khuyết tai, Medpor ear, Polyethylene Implant. 